FILOZOFIA

Roč. 76, 2021, č. 6

DOI: https://doi.org/10.31577/filozofia.2021.76.6.3

\title{
MCDOWELL AND BRANDOM ON OBSERVATIONAL KNOWLEDGE
}

\author{
FILIP ČUKLJEVIĆ, Univerzity of Belgrade, Fakulty of Philosophy, Belgrade, Serbia \\ ČUKLJEVIĆ, F.: McDowell and Brandom on Observational Knowledge \\ FILOZOFIA, 76, 2021, No 6, pp. 423 - 435 \\ In this paper, I will analyze whether John McDowell's critique of Robert Bran- \\ dom's account of observational knowledge is a success. First, I will present \\ Brandom's view of observational knowledge. Then I will lay out the main \\ objections that McDowell raises against it. I will argue that McDowell's argu- \\ ments can be divided into semantic and epistemic. The analysis will show that \\ the epistemic arguments face serious difficulty and that McDowell should focus \\ on semantic critique.
}

Keywords: Observational knowledge - Justification - Reliability - Empirical content - Inference

\section{Brandom's View of Observational Knowledge}

According to Brandom, observational knowledge is knowledge expressed by observational reports. It is manifested by the utterance of (if only in thoughts) propositions like "This is a table", etc., in situations when we attempt to express something about the immediate objects of our perception. We acquire beliefs in these situations not through reasoning but directly, by seeing a table in front of us. ${ }^{1}$ This view of knowledge Brandom calls two-plied. ${ }^{2} \mathrm{He}$ holds that two conditions are needed for observational knowledge: 1 . We must have a reliable differential responsive disposition; ${ }^{3} 2$. We must participate in the game of giving and asking for reasons. ${ }^{4}$

\footnotetext{
${ }^{1}$ Brandom (2002b, 349).

${ }^{2}$ The account of observational knowledge I lay out Brandom not only accepts but attributes to Wilfrid Sellars (Brandom 2002b, 348; Brandom 2010, 322). It remains open as to whether this interpretation of Sellars is correct. As McDowell's view of observational knowledge is largely inspired by Sellars's ideas, the debate between McDowell and Brandom is often concerned with how one should read their predecessor.

${ }^{3}$ Brandom (2002b, 349 - 350).

${ }^{4}$ Brandom (2002b, $\left.349-350\right)$.
} 
The first condition states that a being possessing said disposition will give a different behavioral response to different types of stimuli. ${ }^{5}$ These responses need not always be correct. Certain stimuli must be classified correctly frequently enough - what is needed is reliability. A being possessing this ability need not be human. It can be some other animal - the parrot trained to say the word "red" in the presence of red things. Moreover, a non-living thing, like a thermometer, or even iron, demonstrates the relevant disposition. For this reason, the first condition is not enough for observational knowledge. ${ }^{6}$

What sets us apart from the rest of animals and non-living things is the ability to use concepts. Only humans are capable of giving a response that contains a conceptual content, i.e. of forming beliefs. Contrary to a parrot that classifies stimuli by letting out sounds, humans do this by applying concepts. ${ }^{7}$ Brandom accepts Sellars' view that concept application is a matter of linguistic practice - to understand a concept means to master the use of the corresponding word. ${ }^{8}$ For the utterance of a sentence to represent the application of a concept - to constitute claiming some conceptual content - it must be a move in the game of giving and asking for reasons. ${ }^{9}$ A person uttering the sentence must possess the practical ability to differentiate correct and incorrect inferences in which the terms used in that sentence appear. ${ }^{10}$ To say for a person that they have mastered the term "red", they must tend to consider the inference from the "This is scarlet" to "This is read" a correct one. The same applies for the inference from "This is red" to "This is colored". On the other hand, they must consider incompatible the sentences "This is red all over" and "This is green all over" - they must hold that commitment to one precludes being entitled to another. This practical ability must be socially recognized as sufficient reason for us to say that a person is capable of claiming a certain conceptual content. A person need not know everything implied by the sentence "This is red" for us to say that they have mastered the concept "red". ${ }^{11}$ Adults usually satisfy both of these conditions. That is why our utterance of the sentence "This is red"

\footnotetext{
${ }^{5}$ Brandom holds that a stimulus can be anything that could trigger an adequate response (Brandom 2002a, 96; 2002b, $362-363)$.

${ }^{6}$ Brandom (2002b, $\left.349-350\right)$.

${ }^{7}$ Brandom claims that maybe even animals, objects, etc. have mastered concepts. However, this is different from the way that humans have mastered concepts. Brandom (1996, 250), Brandom (2002b, 350).

${ }^{8}$ Brandom (2002b, 350).

${ }^{9}$ The contents of our claims Brandom calls propositional, semantic, or cognitive, which are terms he uses as synonyms (Brandom 2002b, 351 - 352).

${ }^{10}$ The fact that this ability is practical - that it is knowledge-how, not knowledge-that - is significant for Brandom's inferentialist view of meaning (Brandom1994, 199 - 201).

${ }^{11}$ These inferences are material and not formal. They are not correct based on their logical form but based on their illogical form (Brandom 2002b, 360 - 362).
} 
is a claim, a move in the game of giving and asking for reasons, while in the parrot's case it is merely making noise. ${ }^{12}$

Nevertheless, the ability to operate within the logical space of reasons is insufficient for observational knowledge. ${ }^{13}$ Without the disposition for reliable differentiation of stimuli, our language cannot be about things and events in the world - it cannot be observational. If we are able to make a move in the game of giving and asking for reasons without possessing the mentioned disposition, our claims will have conceptual but not empirical content. This is the case with mathematical sentences. ${ }^{14}$ Hence for our beliefs - knowledge - to be observational, to have empirical content, we have to satisfy both conditions.

The abilities necessary for observational knowledge contribute to the semantic content of the uttered sentences. Operating within the space of reasons provides our claims with conceptual content, while the reliable differential response disposition makes this content empirical. These abilities are also epistemically relevant with regard to their roles within the structure of justification. The main moves in the game of giving and asking for reasons - making claims - are implicitly knowledge claims. ${ }^{15}$ This is why we speak of giving and asking for reasons. When we claim something, we can be asked for the reason on which we base our claim, and we are expected to give a satisfying reason. The reason we offer is the premise of the (material) inference which has as its conclusion the original claim. Thus giving and asking for reasons constitutes the meanings of given sentences.

The space of reasons, besides having an inferential structure, presupposes a certain structure of justification - default and challenge structure. This is reflected in the fact that there are propositions that are in certain situations justified by default and propositions that are open to possible challenges. Someone's belief that $p$ can be justified if $p$ is justified by default. A subject need not justify their belief that $p$ by offering reasons for it. The need to justify belief in this way emerges only in special circumstances when we are presented with good reasons to doubt it. When there are no such challenges the given proposition is justified by default. ${ }^{16}$

In this way, Brandom stops the regress of justification without subscribing to foundationalism. Similarly to the foundationalist framework, Brandom believes that

\footnotetext{
${ }^{12}$ Brandom (2002b, 351).

${ }^{13}$ The term "the logical space of reasons" (or the space of reasons) Brandom takes from Sellars and uses it almost as a synonym for "the game of giving and asking for reasons". To "be" in the space of reasons means to partake in the game of giving and asking for reasons (Brandom 2002b, 351 $352)$.

${ }^{14}$ Brandom (1994, 221 - 222).

${ }^{15}$ Brandom (1994, 200).

${ }^{16}$ Brandom (1994, 204).
} 
a special class of propositions - those justified by default - can serve as reasons that justify other propositions, without themselves demanding such justification. Unlike foundationalist basic propositions, default propositions depend on the context and are not immune to doubt. ${ }^{17}$ Moreover, for $p$ that is justified by default to truly be justified, the lack of an appropriate critique is not enough. The belief that $p$ must be acquired through a reliable method. Here is where the reliable differential responsive disposetion comes to play. It provides beliefs that arise as a consequence of our immediate perception of the world around us with authority. ${ }^{18}$ The ability to operate within the space of reasons enables the epistemic practice within which we use certain claims as reasons for some other claims. The disposition for differential response to stimuli graces special kinds of claims - observational reports - with a privileged status within this practice.

Brandom accepts the definition of knowledge as justified true belief as nominal. Being that his general methodological assumption is that normative statuses (like knowledge) should in some way be explained by normative attitudes (like attributing knowledge), he focuses on what it means to attribute knowledge to someone. ${ }^{19}$ When we attribute knowledge to $S$, we do three things: 1 . We attribute to $S$ a certain type of commitment. We treat them like they have accepted a certain proposition and made a move in the game of giving and asking for reasons. In this way, they have committed themself to accept propositions that follow from the original one, as well as not to accept propositions that are incompatible with it. This is in line with the traditional belief condition; 2. We must attribute to $S$ an entitlement for accepting a given proposition. Thus the justification condition is satisfied. Sometimes we attribute entitlement if $S$ can give adequate reasons to support their belief. Sometimes they can be entitled to accept a proposition by default; 3 . We who attribute knowledge to $S$ must ourselves endorse relevant proposition. This way we suppose that $S$ 's belief is not only justified but true. When accepting a proposition we do not have to be aware of all of its consequences, but we are committed to endorsing all of them..$^{20}$

For observational beliefs to be justified it is enough that we reliably classify relevant things. How do we attribute reliability to someone? By accepting the correctness of the reliability inference. When $S$ 's belief is acquired through a reliable method we consider it probably true. We treat $S$ as reliably believing that $p$ by accepting

\footnotetext{
${ }^{17}$ Brandom (1994, 205 - 206).

${ }^{18}$ Brandom (1994, $\left.222-223\right)$.

${ }^{19}$ Brandom (1994, 212).

${ }^{20}$ Brandom (2000, $\left.118-119\right)$.
} 
" $S$ believes $p$; therefore, $p$ " as a valid argument. ${ }^{21}$ We do not have to be able to explicitly formulate this argument. It is enough if we implicitly accept it as valid in our practice.

This view of reliability, Brandom argues, has another significant advantage. It offers a satisfactory explanation of the scenario presented by Alvin Goldman. Imagine that a physiologically normal subject in normal circumstances is observing a barn in front of them. This causally results in them forming the belief that a barn is in front of them. Furthermore, this belief is true. However, the subject is in an area where the barn in front of them is the only real one, while there are 999 extremely convincing barn facades. ${ }^{22}$ Do they know that there is a barn in front of them? Brandom holds that it is difficult to say that they do. He accepts Goldman's idea that the reason they do not possess knowledge is that they are not reliable in the given circumstances. ${ }^{23}$

Brandom does not believe that this insight can justify us in viewing reliability in a completely naturalistic way, as something depending only on whether or not someone's belief has a large enough objective probability to be true. What if the barn is located in a state where $99 \%$ of barns are authentic? Can the subject then be said to possess knowledge? What if the state is located in a world where $99 \%$ of barns are fake? The conclusion to which Brandom arrives is that attributing reliability depends on the determination of a reference class in relation to which reliability is assessed. This class cannot be determined by nature, but by us. ${ }^{24}$ Different reference classes correspond to different presuppositions that knowledge attributer might have. If we accept the presupposition that the subject to whom we attribute knowledge is located in a problematic area, inference based on reliability will not be correct. But if we presuppose that they are in a given state, it will be. There is no contradiction because these are not the same inferences, as the former contains an additional presupposition. This presupposition can affect the correctness of inference, because it is material and not deductive. ${ }^{25}$

\section{McDowell's Critique of Brandom's View of Observational Knowledge}

McDowell's critique can be divided into semantic and epistemic. He does not make this distinction, nor does he offer any similar distinction of his arguments. Commentators of the debate between McDowell and Brandom do not offer this kind of distinction nor something similar either. ${ }^{26}$ However, I believe that this distinction is useful. It can help

\footnotetext{
${ }^{21}$ Brandom (2000, $\left.119-120\right)$.

${ }^{22}$ Brandom (2000, $\left.113-114\right)$.

${ }^{23}$ Brandom $(2000,114-115)$.

${ }^{24}$ Brandom (2000, $\left.116-118\right)$.

${ }^{25}$ Brandom $(2000,120-121)$.

${ }^{26}$ Huemer (2005), Olsen (2009), Barber (2011).
} 
us gain a better understanding of McDowell's arguments against Brandom, as well as determine how successful they are.

The criterion for this distinction is reached in the following way. McDowell and Brandom essentially accept the standard definition of knowledge. By attacking Brandom's view, McDowell intends to show that the examples Brandom mentions as authentic cases of observational knowledge do not satisfy some of the necessary conditions for knowledge. Brandom's favorite example is chicken sexers. He stresses that these people not only do not know based on what they are sorting chicks but they do not know whether or not they are reliably doing so. Therefore, they cannot bring up their reliability as a justification for their beliefs. However, according to Brandom, these persons do possess the knowledge and it is observational. ${ }^{27}$

Without questioning the condition of truth, McDowell's objections aim towards the remaining two necessary conditions for knowledge. The semantic critique targets the belief condition. ${ }^{28}$ Following this line of argument, McDowell claims Brandom's example of so-called observational knowledge lacks observational beliefs. The mentioned subjects' beliefs have no empirical content whatsoever, hence they are not observational. On the other hand, the epistemic critique questions the justification condition. ${ }^{29}$ According to this line of argument, the given examples do not contain the type of justification necessary for knowledge to be observational. Observational beliefs must not be justified inferentially if they are to constitute observational knowledge. Because McDowell holds that observational knowledge as viewed by Brandom has an implicit inferential structure, it is therefore not observational knowledge at all.

First I shall discuss the epistemic critique, and then the semantic one. Brandom, McDowell, and commentators have all given more space to arguments that fall under the semantic critique. ${ }^{30}$ As I hold that the semantic critique presents more clearly the main point of dispute between McDowell and Brandom, as well as that it has more chances of success than the epistemic one, I aim to demonstrate that the focus should stay on the semantic argument. However, all participants in this debate need to have in mind the precise target of this critique. This needs to be stressed because both in McDowell's and Brandom's works, but also in secondary sources, the two types of

\footnotetext{
${ }^{27}$ According to Brandom, the possibility of these cases represents the main externalist insight that he accepts (Brandom 2000, 98 - 99; $102-103$ ).

${ }^{28}$ This is why it is called this way. "Belief" is not a technical term used by Brandom to develop his inferentialism. For this he uses the concept of discursive commitment (Brandom 1994). Because Brandom uses this idea to try to explain the concept of meaning, that is semantic content, I find it adequate to name the critique that questions the belief condition "semantic".

${ }^{29}$ Being that justification is one of the central problems in epistemology, I call this critique "epistemic".

${ }^{30}$ Huemer (2005), Olsen (2009), Barber (2011).
} 
critique are often intertwined, which can prevent us from clearly viewing their targets as well as the success of their attacks.

\section{The Epistemic Critique}

The main epistemic argument offered by McDowell brings into question Brandom's distinction between inferential and non-inferential knowledge. According to Brandom, knowledge is inferential iff the subject de facto arrives at the corresponding belief through reasoning. Otherwise, knowledge is non-inferential. McDowell believes that this distinction is psychological, while it should be epistemological. That is why he offers his definition of inferential knowledge, which states that knowledge is inferential iff we need to refer to the correctness of a certain inference in order to justify the corresponding belief. A chicken sexer will have the non-inferential knowledge, if we are to follow Brandom's view, because they arrive at their belief not through reasoning but due to a disposition for making certain differentiation. However, according to McDowell, this knowledge will be inferential. In order to demonstrate that the said person's belief is the actual knowledge we need to take into account the person's reliability - we have to refer to Brandom's reliability inference. ${ }^{31}$

Brandom defends his view by claiming that the way in which belief is acquired need not only be psychologically relevant but can also be epistemically relevant. What differentiates observational knowledge from knowledge acquired from memories or testimonies is precisely the process through which it was acquired. If we want to justify some belief based on memory we will say that we remember so-and-so. In the case of observational reports we will say that we see so-and-so. Appealing to memory and sight does not serve as a premise in an argument by which we justify our belief. Instead, in that way we point to the process by which the belief was formed. ${ }^{32}$

Although these observations seem valid, they nevertheless fail to dull the cutting edge of McDowell's critique. What about reliability inference? According to Brandom's view of (attributing) knowledge, we need to refer to that inference if we want to show that a certain observational belief is knowledge. How are we to understand the previously mentioned remarks of Brandom in light of his view of observational knowledge? Brandom's comments are not a direct response to McDowell. It seems that if we do not explicitly reject McDowell's criterion for inferential knowledge, which Brandom does not do, the two-plied view of observational knowledge will contain an inferential component.

Faced with this challenge, Brandom turns to a conciliatory solution. He holds that the difference between McDowell and himself is primarily of verbal nature. It makes no

\footnotetext{
${ }^{31}$ McDowell (2010, $\left.141-142\right)$.

${ }^{32}$ Brandom (2010, 324).
} 
difference whether or not we claim, like Brandom, that there are two cases of observational knowledge - one in which the subject cannot offer an inferential justification for their belief (chicken sexers not aware of their reliability) and the other in which they can offer this justification (chicken sexers aware of their reliability) - or hold, like McDowell, that there are two types of inferential knowledge - one which the subject has reached through an inferential process (the knowledge that a certain mathematical proposition is a theorem) and one to which they have arrived with the reliable differential response disposition (chicken sexers not aware of their reliability). ${ }^{33}$

I find this response too conciliatory. One gets the impression that McDowell is the winner of this agreement because it seems that Brandom's observational knowledge contains a significant inferential element, which was McDowell's accusation from the start. I believe that Brandom should try to give a better response. That response should show that McDowell's criterion is inadequate and that observational knowledge does not have an implicit inferential structure.

Crucial for this response is the following question. Is de facto attribution of reliability to a subject, which entails the determination of a relevant reference class, necessary for the subject's belief to be justified, or is it sufficient for such attribution to be merely possible? In the first case, in order for a subject to know that $p$ we must have someone actually determining relevant reference class in the form of reliability inference concerning that subject. On the other hand, according to the second option, someone may know that $p$ even if no one actually attributes to them that particular piece of knowledge. That is, the actual determination of relevant reference class by attributer does not need to take place in order for a subject to know that $p$. Naturally, they must receive many other knowledge attributions in the first place in order to count at all as a subject capable of knowledge. Furthermore, it must be possible for that subject to receive attributions of knowledge that $p .^{34}$ Since the second option seems more plausible, and certain paragraphs in Brandom's work suggest that he was inclined to this option, I believe we should read him as if that is the option he chooses. ${ }^{35}$ Some authors do not make the previous distinction which is why they seem to interpret Brandom as accepting the first option, which in my view should be avoided. ${ }^{36}$

With this in mind, Brandom might argue that McDowell's criterion for inferential knowledge is inadequate, or at least unnecessary rigorous. Why would a subject's knowledge be inferential if in order for a relevant belief to be justified it must be merely possible for someone to attribute reliability to that subject? The subject's knowledge is

\footnotetext{
${ }^{33}$ Brandom (2010, 325).

${ }^{34} \mathrm{I}$ wish to thank an anonymous reviewer for this insight.

${ }^{35}$ Barber (2011, 92), Brandom (2000; 99; 101; 103; 105 - 106).

${ }^{36}$ Huemer (2005, 64), Barber (2011, 10).
} 
not justified due to someone actually attributing reliability to them, but because it is merely possible for such attribution to take place. Yet, McDowell could still insist that even in that case, in the final analysis it would be inferential knowledge. $S$ would observationally know that $p$ iff it is possible for someone to attribute reliability to $S$, which presuposses giving consideration to reliability inference. Thus it is inevitable to take into account inference at some point in order to explain a subject's observational knowledge.

Although Brandom seems to be guilty of what McDowell charges him, concerning that his account of observational knowledge inevitably presupposes an implicit inferential element, he might bite the bullet and accept that this is inevitable. However, he might retain that his account is still to be preferred to McDowell's. He could attack McDowell's alternative according to which the possession of direct, sensuous experience is crucial for the justification of observational knowledge.

Brandom could claim that his view of observational reports contains a significant advantage over McDowell's - it offers a plausible explanation as to why the subject does not possess knowledge in Goldman's scenario. On the other hand, he might emphasize that it is not clear how McDowell's focus on direct, sensuous experience could explain this case. The assumption is that the subject sees a real barn in front of them and their experiential evidence is completely in order. However, this is apparently not enough for us to say that they know that there is a barn in front of them. There might not be an overarching reason why McDowell, like Goldman and Brandom, could not refer to the subject's unreliability in the given circumstances in order to explain their lack of knowledge. But in this case, since (un)reliability turns out to be of key importance for the justification of empirical knowledge, the question arises as to what role does direct, sensuous experience has in this justification? If reliability is what we use to explain how our observational belief is justified, it might not be economical, nor theoretically desirable, to include direct, sensuous experience into this account. This way Brandom could say that McDowell's alternative view of the justification of observational beliefs lacks proper motivation.

McDowell could insist on his disjunctivism, that is the claim that subject is in different mental states when they have veridical experience and when they are presented with the deceptive case. As McDowell claims, an appearance that $p$ can be either a mere appearance or the fact that $p$ making itself perpetually manifest to a subject. ${ }^{37}$ The fact that subject cannot make any distinction between those two experiences has no significance. The "highest common factor" model, according to which the object of experience is in general mere appearance, ${ }^{38}$ with veridical experience being connected

${ }^{37}$ McDowell (1998, 386 - 387, 389).

${ }^{38}$ McDowell (1998, 388). 
to the world in causally adequate sort of way, while in deceptive case the same kind of experience is not connected in that way, is thus rejected. ${ }^{39}$

I will not go here into further details of this position. McDowell has his reasons for this view, and it is impossible in this paper to analyze all advantages of Brandom's position over McDowell's, and vice versa. Still, Goldman's scenario remains a great problem for McDowell in my opinion, ${ }^{40}$ and an important asset for Brandom's position. A person in Goldman's scenario may have, in McDowell's view, a veridical experience of a barn in front of them. Still, it seems completely reasonable to ask whether they have justification for their belief if they are, for example, situated in an area where $99 \%$ of barns are fake. Furthermore, the answer to this question seems to be negative. On the other hand, the implicit inferential component present in Brandom's account of observational knowledge - reliability inference - ia precisely what allows Brandom to offer a satisfactory solution to this problem.

This is how Brandom could try to counter McDowell's objection that the two-plied view of observational knowledge contains an implicit inferential element, and point out that McDowell's framework cannot in a satisfactory way explain what is happening in Goldman's scenario. I do not see how could McDowell give a clear and satisfying answer to this problem. Because of this, I believe that his insistence on the need for a rational link and the relation of justification between our thoughts and direct experiential content, in order for them to be about the outer world and thus constitute knowledge, should be understood in the sense that it points out the necessity of this connection for there even to be beliefs about the world at all. The arrow of McDowell's critique of Brandom's view of observational reports, in my belief, should target the alleged satisfaction of the belief condition, and not the justification condition for knowledge.

\section{The Semantic Critique}

The semantic critique is based on McDowell's conviction that Brandom's view of observational knowledge cannot adequately explain how such knowledge obtains its empirical content. If the given belief has no empirical content it will not be of the observational type, nor will there be observational knowledge..$^{41}$ Although this critique

\footnotetext{
${ }^{39}$ McDowell (1998, 385 - 394).

${ }^{40}$ McDowell does briefly mention Goldman's scenario in a footnote in "Criteria, Defeasibility, and Knowledge". Unfortunately, I find it far from clear what, if anything, could be made out of it in order to provide a satisfactory response to the problem Goldman's scenario presents us with. McDowell (1998, 390).

${ }^{41}$ McDowell occasionally goes a step further, claiming that Brandom's examples of observational knowledge lack not only empirical content but conceptual content as well. This would mean that these examples lack observational beliefs, as well as beliefs in general McDowell $(1994,26)$, Wanderer $(2008,193-194)$.
} 
takes the form of several arguments McDowell had offered in various works, the main argument from which all others stem points out to the non-existence of experience of that which one purports to report about. For the chicken sexers from Brandom's example, although inclined to claim that there is a (fe)male chick in front of them, are not aware of anything in their direct, sensuous experience on the basis of which they make this claim. The case would probably be different if they were to sort out human babies based on their sex. That is why McDowell argues that these persons' reports are just a blind reaction to certain stimuli and not a rational response to what they have encountered in experience. For the given report to have empirical content, the fact that there is a (fe)male chick in front of them must be given in a direct manner in experience to the person reporting. ${ }^{42}$

McDowell holds that his view of experience as conceptually structured enables this condition to be met. On the other hand, in Brandom's case, the first-person perspective does not play a significant role - the attribution and assessment of knowledge are done from a third-person perspective. For McDowell, this is unacceptable. As he says, the facts need to be given directly in experience for our reports about them to be rationally constrained by these facts. If our claims are not constrained they do not represent a rational response to events in the world, but are their mere causal consequences. They have no empirical content. ${ }^{43}$

By aiming to disprove the possibility of Brandom's theory to explain where our claims get their empirical content from, McDowell goes beyond the boundaries of primarily epistemological discussions. He holds that Brandom's central philosophical idea - the inferential theory of meaning - is wrong. This, however, leads to the question of the nature of the relation between inferential and representational elements within an adequate theory of meaning. The answer to this question is one of the main points of dispute between McDowell and Brandom. ${ }^{44}$ Given the scope and intention of this paper, I will not tackle it here. What is crucial is that by negating the presence of empirical content in the reports of chicken sexers and the like, McDowell claims that these persons, essentially, do not understand what they purport to claim with their reports. Since they lack the necessary understanding, they do not have genuine beliefs about the world.

Can Brandom's model of observational knowledge capture all the complexities involved in our beliefs about the world around us? Can we, to a significant extent, ignore

42 McDowell (2002, 280), McDowell (2010, 140 - 141).

${ }^{43}$ Barber (2011, 24 - 25), McDowell (1996, 297 - 298). As some notice, McDowell included, this raises a deeper problem - what is doubted is not only the possibility of knowledge but also the possibility of intentionality (Maher 2012, 96; Wanderer 2008, 193 - 194).

${ }^{44}$ For more on this see Barber $(2011,1-9)$. 
the first-person perspective while maintaining that we have successfully analyzed all the components involved in a fully human phenomenon of observational beliefs? Brandom thinks that in order to explain the phenomenon of observational knowledge it is sufficient for us to focus on two dimensions: 1) Possesion of a reliable differential responsive disposition; 2) Participation in the game of giving and asking for reasons. While this might be sufficient in order to show how observational beliefs are justified, ${ }^{45}$ it is another question whether it is sufficient to adequately explain how observational beliefs have empirical content, that is, how they count as (empirical) beliefs at all in the first place.

We could perhaps imagine an advanced artificial intelligence that would satisfy Brandom's conditions for observational knowledge. It would have a reliable differential responsive disposition, and it could participate in the game of giving and asking for reasons to a level we deem sufficient for us to count it as having abilities above the level of mere animals and non-living things. We might even say that it, in a certain sense, engages in conceptual activity similar, or very close, to our own. Furthermore, perhaps we might say that, for all the practical purposes, this advanced AI could be taken as a member of our discursive community. This would be much easier to entertain if we imagine it as looking just like a human being. In that case, we could interact and converse with it without ever doubting that there is something "different" about it that sets it apart from the rest of us.

Still, is it really just "one of us"? Is this a factual question at all, or, perhaps, a matter of some kind of a decision on our part, a matter of practical stance that we take towards it in our everyday interactions with it? I think that Brandom would take this, "pragmatic", kind of attitude towards this question. On the other hand, I believe that McDowell has a strong intuition that there is something important that this advanced AI would lack in order to be just "one of us", that is, in order to truly have humanlike observational beliefs. He would insist that, in the final analysis, all the practical purposes set aside, it would not do justice to a fully human phenomenon of observational beliefs to omit direct sensuous experience available to us from the first-person perspective that is involved in this phenomenon.

\section{Bibliography}

BARBER, M. (2011): The Intentional Spectrum and Intersubjectivity. Athens: Ohio University Press. BRANDOM, R. (1994): Making It Explicit. London: Harvard University Press.

BRANDOM, R. (1996): Perception and Rational Constraint: McDowell's Mind and World, In: Villanueva, E. (ed.): Perception. Atascadero: Ridgeview Publishing, 241 - 259.

BRANDOM, R. (2000): Articulating Reasons. London: Harvard University Press.

BRANDOM, R. (2002a): Non-inferential knowledge, perceptual experience, and secondary qualities,

${ }^{45}$ For a different opinion see Williams $(2008,163)$. 
In: Smith, N. H. (ed.): Reading McDowell: On Mind and World. London: Routledge, 92 - 105. BRANDOM, R. (2002b): Tales of the Mighty Dead. Cambridge: Harvard University Press.

BRANDOM, R. (2010): Reply to John McDowell's "Brandom on observation", In: Weiss, B. Wanderer, J. (eds.): Reading Brandom: On Making It Explicit. London: Routledge, 320 - 326.

HUEMER, W. (2005): The Constitution of Consciousness. London: Routledge.

MAHER, C. (2012): The Pittsburgh School of Philosophy. London: Routledge.

McDOWELL, J. (1994): Mind and World. Cambridge: Harvard University Press.

McDOWELL, J. (1996): Reply to Gibson, Byrne, and Brandom, In: Villanueva, E. (ed.): Perception. Atascadero: Ridgeview Publishing, 283 - 300.

McDOWELL, J. (1998): Criteria, Defeasibility, and Knowledge, In: McDowell. J. (ed.): Meaning, Knowledge, and Reality. Cambridge: Harvard University Press, 369 - 394.

McDOWELL, J. (2002): Responses, In: Smith, N. H. (ed.): Reading McDowell: On Mind and World. London: Routledge, $269-305$.

McDOWELL, J. (2010): Brandom on observation, In: Weiss. B. - Wanderer, J. (eds.): Reading Brandom: On Making It Explicit. London: Routledge, 129 - 144.

OLSEN, N. S. (2009): Reinterpreting Sellars in the Light of Brandom, McDowell, and A. D. Smith. European Journal of Philosophy, 18 (4), 510 - 538.

WANDERER, J. (2008): Robert Brandom. Montreal: McGill-Queens's University Press.

WILLIAMS, M. (2008): Science and Sensibility: McDowell and Sellars on Perceptual Experience, In: Lindgaard, J. (ed.): John McDowell: Experience, Norm, and Nature. Malden: Blackwell Publishing, $152-175$.

Filip Čukljević

University of Belgrade

Faculty of Philosophy

Čika Ljubina 18-20

11000 Belgrade

Serbia

e-mail: filipcukljevic@gmail.com

ORCID ID: https://orcid.org/0000-0001-9188-9260 